\title{
Richter, Jan Friedrich, Claus Berg. Retabelproduktion des Spätmittelalters im Ostseeraum
}

\section{Marie-Louise Pelus-Kaplan}

\section{OpenEdition}

\section{Journals}

Édition électronique

URL : http://journals.openedition.org/ifha/1698

DOl : 10.4000/ifha.1698

ISSN : 2198-8943

Éditeur

IFRA - Institut franco-allemand (sciences historiques et sociales)

Référence électronique

Marie-Louise Pelus-Kaplan, «Richter, Jan Friedrich, Claus Berg. Retabelproduktion des Spätmittelalters im Ostseeraum », Revue de l'IFHA [En ligne], Date de recension, mis en ligne le 01 janvier 2008, consulté le 22 septembre 2020. URL : http://journals.openedition.org/ifha/1698 ; DOI : https://doi.org/10.4000/ ifha. 1698

Ce document a été généré automatiquement le 22 septembre 2020.

(C)IFHA 


\title{
Richter, Jan Friedrich, Claus Berg. Retabelproduktion des Spätmittelalters im Ostseeraum
}

\author{
Marie-Louise Pelus-Kaplan
}

L'homogénéité culturelle et artistique de l'espace baltique à l'époque de la Hanse (Moyen Âge et débuts des temps modernes) est un fait bien connu. L'unité de cette civilisation urbaine repose au premier chef sur la splendeur du " gothique de briques " qui donne aux églises, aux maisons, aux hôtels de ville leur cachet si particulier. Il ne s'agit pas seulement d'une unité de façade. À l'intérieur des bâtiments, religieux ou laïcs, nous serons, de nouveau, frappés par les similitudes, les correspondances, les échos. À la charnière entre Moyen Âge et Renaissance, ce vaste espace qui va, grosso modo, des Pays-Bas aux frontières de la Russie, englobant la Scandinavie et la moitié septentrionale de l'Allemagne et de la Pologne, a été marqué par le rayonnement de quelques grands artistes très connus, tels le peintre Michel Sittow, ou le peintre et sculpteur lübeckois Bernt Notke, dont les œuvres se retrouvent non seulement dans les principales capitales nordiques de l'époque (Lübeck, Stockholm, Reval), mais également dans de très nombreuses petites villes, sur tout le pourtour de l'espace baltique.

Plus jeune, le sculpteur de retables Claus Berg, né lui aussi à Lübeck en 1475, est en partie son contemporain, mais son style s'en écarte de façon radicale. Sollicité dès 1503 par la reine Christine de Danemark, c'est dans ce royaume, installé dès avant 1507 à Odense, qu'il réalise ses œuvres principales. Berg est alors à la tête du plus important atelier de sculpture de tout le Danemark. Il quitte vers 1532 le royaume au moment où celui-ci, déchiré par une guerre civile, bascule vers le luthéranisme. C'est en Mecklembourg que l'on trouve ses dernières œuvres; on ignore la date exacte de sa mort, située aux alentours de 1535.

Claus Berg n'était jusqu'ici nullement un inconnu. Si le monument funéraire du roi Jean de Danemark et de sa famille dans le chœur de l'ancienne église du cloître des Franciscains à Odense est sa réalisation la plus fameuse, de très nombreuses autres œuvres, au Danemark, en Allemagne, lui ont été attribuées, parfois un peu vite, puis 
retirées. Rendre à Berg le catalogue de ses œuvres, et à d'autres artistes, ses élèves ou ses contemporains, celles qui leur reviennent, tel est l'objectif du savant ouvrage de J.F.R., splendidement illustré : nombreuses photographies en noir et blanc, quelques cartes, et une douzaine de planches en couleurs.

Après une présentation du contexte historique troublé de la Scandinavie dans le premier tiers du XVIe s., contexte qui eut son influence sur les commandes des mécènes de la noblesse et du clergé, l'auteur procède à une analyse détaillée des œuvres de Berg : l'ensemble d'odense d'abord, puis une abondante série d'autres retables, de croix triomphales, de monuments funéraires (" épitaphes »), ainsi que des chaires, des statues de saints. Le musée Sainte-Anne de la ville de Lübeck, sa patrie, renferme une de ses sculptures les plus anciennes, une statue de la Vierge destinée à l'hôpital du Saint-Esprit. Chacune de ces œuvres fait l'objet d'une description minutieuse accompagnée de photos.

Les chapitres suivants sont consacrés, l'un aux "sculpteurs associés " auxquels Claus Berg, submergé de commandes, devait faire appel, l'autre aux sculpteurs influencés par Berg sans avoir directement travaillé pour lui, artistes dont on ignore les noms, répertoriés comme « le maître de » suivi d'un nom de lieu ou d'église. Les peintres qui ont collaboré aux retables sont en revanche mieux connus. L'atelier d'Ivar Pedersen et Peder Mahler est associé à presque toutes les œuvres de Berg comportant des peintures ; quelques-unes néanmoins sont d'une autre équipe, celle d'Erhard Altdorfer.

L'étude du « contexte stylistique » de l'œuvre de Claus Berg, dont le style mouvementé, très expressif se distingue nettement de celui de Bernt Notke, amène à penser que, si une collaboration de l'artiste à l'atelier de Veit Stoss n'est pas exclue, l'influence du maitre de Nuremberg, associée à celle de Riemenschneider, est de toute manière indéniable, ainsi que celle des gravures de Cranach et de Dürer. Une analyse poussée de l'importante masse d'œuvres d'art (sculptures et retables) réalisées à l'époque de Berg en Allemagne septentrionale et en Scandinavie conduit à la conclusion que, plutôt que comme le fondateur d'une école largement étendue, Berg, qui domine incontestablement la production danoise, apparaît comme un créateur relativement isolé dans le cadre plus vaste de l'Europe du Nord. Si beaucoup d'autres œuvres dans ce large espace s'apparentent aux siennes, c'est qu'il est en fait l'aîné et le plus connu de tout un groupe de sculpteurs lübeckois qui ont été, comme lui, formés dans l'entourage de Veit Stoss et de Riemenschneider. Parmi eux, le Maître de la Sainte Famille de la Burgkirche de Lübeck, ou celui du maitre autel de Prenzlau. Les élèves de ce dernier, tel Benedikt Dreyer, exportent à partir de Lübeck dans tout l'espace baltique le style nouveau venu du Sud de l'Allemagne. Berg dans ce contexte est donc plus un précurseur que le chef d'une école nouvelle, marquée directement par l'influence des maîtres d'Allemagne du Sud.

Marie-Louise Pelus-Kaplan (Université Denis-Diderot - Paris VII) 